\title{
The Electromagnetic Design and Optimization of Permanent Magnet Synchronous Electro-spindle for Turning Machine
}

\author{
Yan $\mathrm{Li}^{1}$, Jianing Yan ${ }^{1,}$, Jiakuan $\mathrm{Xia}^{2}$ \\ ${ }^{1}$ Research Institute of Special Electric Machines, Shenyang University of Technology, China \\ ${ }^{2}$ School of Electric Engineering, Shenyang University of Technology, China \\ aemail: yanjianing930@163.com
}

Keywords: Turning electro-spindle, PM, Electromagnetic design, Rotor structure optimization, Weakening ability

\begin{abstract}
As the wide application of permanent magnet (PM) synchronous electro-spindle in turning machine, a Siemens 1FE1 built-in water-cooled PM synchronous electro-spindle is taken as a reference, and the electromagnetic design and simulation is analyzed by finite element software Ansoft in this paper. On the basis of the simulation results meet for the design requirements, the rotor structure is optimized, so the harmonic content of the air-gap flux density and the torque ripple are both effectively reduced. Finally, the weakening ability of the motor is checked, for electromagnetic design and weakening calculation of similar motor has an important engineering practicality.
\end{abstract}

\section{Introduction}

In this paper a new optimal design of soccer robot control system which is based on mechanical analyses and calculations on the pressure and transmutation states of chip kick mechanics, this new control system with high precision for speed control and high dynamic quality.

With the rapid development of China's equipment manufacturing industry, CNC machine tools is becoming more and more high-speed, high-precision, high efficiency and high intelligence, and electro-spindle CNC machine tools has become one of the core features of the most able to adapt to these conditions of high performance. The hollow rotor kit directly on the machine spindle, and the stator side with a cooling jacket is mounted in the spindle housing units, which called built-in electro-spindle. Compared to the currently widely used asynchronous type electro-spindle, PM synchronous electro-spindle with greater rate of density, more compact, higher efficiency and power factor and many other advantages, represents the future development trend of electro-spindle[1].

However, due to the special structure of PM synchronous electro-spindle and the limited space of the machine tool, the source of electro-spindle is mainly dependent on imports, and there is not much about the design and analysis of electromagnetic research, and the design methods also rely mainly on experience and analogy, so it is difficult to design a high efficiency and high-precision synchronous electro-spindle products.

In this paper, a electromagnetic program of PM synchronous electro-spindle for turning has been designed based on the Siemens 1FE1 series built-in electro-spindle motor, and the finite element software Ansoft is used to analyzed the electromagnetic field of the motor simulation. The steady magnetic field cloud distribution figure and the air-gap flux density distribution curve are given. And the electromagnetic torque and rated current are calculated by transient solver. On this basis, the motor rotor structure were optimized and the three-phase no-load EMF is caculated. Finally the weakening ability is checked.

\section{Electromagnetic Design of Turning Electro-spindle}

According to Siemens official data, there are two kinds of 1FE1 series of built-in water-cooled electro-spindle for synchronous motors-high torque and high rotational speed series. According to 
the twice weakening speed range demand of turning machine, this article intends to design a multiple of two times of weakening ability of turning power electro-spindle motor, reference technical data of motor $1 \mathrm{FE} 1093-6 \mathrm{WN}$ : Rated power $36.6 \mathrm{~kW}$, rated torque $100 \mathrm{Nm}$, rated speed 3500rpm, maximum speed 7000rpm, rated current $83 \mathrm{~A}$, rotor and stator weight $41 \mathrm{~kg}$, stator outside diameter of $180 \mathrm{~mm}$, rotor inside diameter $92 \mathrm{~mm}$, armature core length $150 \mathrm{~mm}$, 6-pole 36 slot. Accordingly the technical requirements of the designed motor is shown in Tab.1.

Tab.1 The technical requirements

\begin{tabular}{cccccccc}
\hline $\begin{array}{c}\text { Rated } \\
\text { power }\end{array}$ & $\begin{array}{c}\text { Rated } \\
\text { current }\end{array}$ & $\begin{array}{c}\text { Rated } \\
\text { speed }\end{array}$ & $\begin{array}{c}\text { Maximum } \\
\text { speed }\end{array}$ & $\begin{array}{c}\text { Outer diameter } \\
\text { of stator }\end{array}$ & $\begin{array}{c}\text { Internal diameter } \\
\text { of rotor }\end{array}$ & Length & Poles and slots \\
\hline $28 \mathrm{~kW}$ & $45 \mathrm{~A}$ & $3000 \mathrm{rpm}$ & $6000 \mathrm{rpm}$ & $180 \mathrm{~mm}$ & $92 \mathrm{~mm}$ & $150 \mathrm{~mm}$ & 6 poles 36 slots \\
\hline
\end{tabular}

1. The rotor structure choice

The $d$-axis inductance of interior PM synchronous motor is bigger than surface PM synchronous motor, and with a good weakening speed expansion capacity, therefore we take the interior "one" shaped rotor structure[2].

\section{The design of the stator laminations and winding}

In this paper, the electro-spindle shaft is thick, the result of the stator outer diameter $180 \mathrm{~mm}$ subtracte the inner diameter $92 \mathrm{~mm}$ is not too big, so it must be comprehensive considered in order to determine the stator yoke and the rotor yoke thickness. Reference Y2 series induction motor, the stator geometries using pear-shaped groove, as pear-shaped slot with high slot utilization and long life. Also the use of parallel tooth structure is to reduce the number of variables notching, and punching using $0.5 \mathrm{~mm}$ thick silicon layers together, help to reduce the stator eddy current loss[3]. The designed stator lamination and slot size is shown in Fig.1(a):

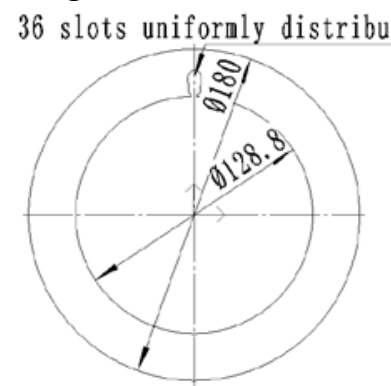

(a)Stator laminations and slot size

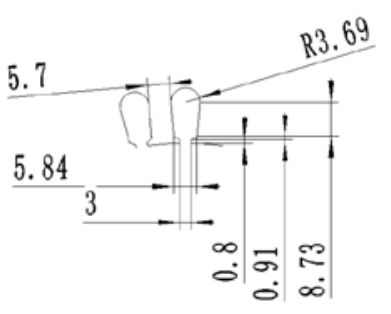

Fig.1 Stator and rotor size

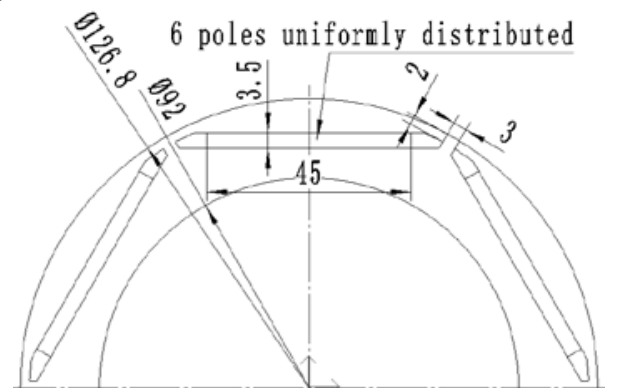

(b) Rotor pole size

In order as far as possible to meet the weakening condition, a higher winding coefficient kdp1 of the winding is beneficial. Whole integer slot winding pitch has the highest kdp1, but the harmonic content is higher, and take the convenience of embedding the motor winding into consideration, the single whole winding, 26 conductors per slot and each number of starands 2, line diameter of $0.96 \mathrm{~mm}$, parallel branch number 3, the stator skew, materials for DW315 are designed.

3. The design of air gap length and pole arc coefficient

For induction motors, the air gap length is in accordance with empirical formula to find

$\delta=0.3\left(0.4+7 \sqrt{D_{i 1} l_{\text {ef }}}\right) \times 10^{-3}$

Where, $\delta$ - air gap length, $D_{i 1}$ - internal diameter of stator, $l_{e f}$ - armature core length.

As for the PM synchronous motor, which is generally a larger gap length $0.1 \sim 0.2 \mathrm{~mm}$ to the specifications of the induction motor, which can improve the efficiency of PM motor and the overload multiples[4]. In this paper, the designed motor gap length is $1 \mathrm{~mm}$.

The value of the motor pole arc coefficient determines the width of the PM poles (and thus indirectly determines the motor no-load flux, inductance and other parameters), and the value of harmonic content of flux density. In this paper, the motor poles arc coefficient is designed as 0.8 when take the influence of arc coefficient to no-load flux and sine waveform distortion rate of air gap flux density as a key consideration. 
4. The design of PM size and material selection

The PM poles magnetization direction of the length and width can be estimated preliminary as follow

$$
\left\{\begin{array}{l}
h_{M}=\frac{\mu_{r}}{\frac{B_{r}}{B_{\delta}}-1} \delta \\
b_{M}=\alpha_{P} \tau_{2}
\end{array}\right.
$$

Where, $B_{r} / B_{\delta}$ - ratio between the density of magnetic material remanence and no-load flux density, generally $1.1 \sim 1.35, \mu_{r}$-relative permeability of magnetic material, $\tau_{2}$ — rotor pole distance, $\alpha_{p}$ - pole arc coefficient.

The PM magnetic pole magnetizing direction length and the width of the initial design value is given by formula(2), and amend the value with the relative size of the magnetic bridge. After a lot of calculations and comparisons, PM pole magnetization direction is taken as the length and width, respectively, 3.5 and $45 \mathrm{~mm}$, material $\mathrm{NdFe} 35$.

In this paper, the shape design of the rotor is shown in Fig.1(b).

\section{FEA Analysis of Electromagnetic Field}

Accurate electromagnetic calculations is one of the important basis to verify the feasibility of the motor structure. When the stator winding, rotor magnetic circuit, magnetic pole size are determined, the finite element method is used to analysis the electromagnetic feild.

Fig. 2 is the steady magnetic field cloud distribution figure, its highest flux density of the tooth portion does not exceed $1.4 \mathrm{~T}$, which is not saturated, and the magnetic bridge which is oversaturated effectively limit the magnetic flux leakage. Due to the shaft is thick , the rotor yoke is smaller compared with specifications PM synchronous motor, making its rotor yoke flux density higher.
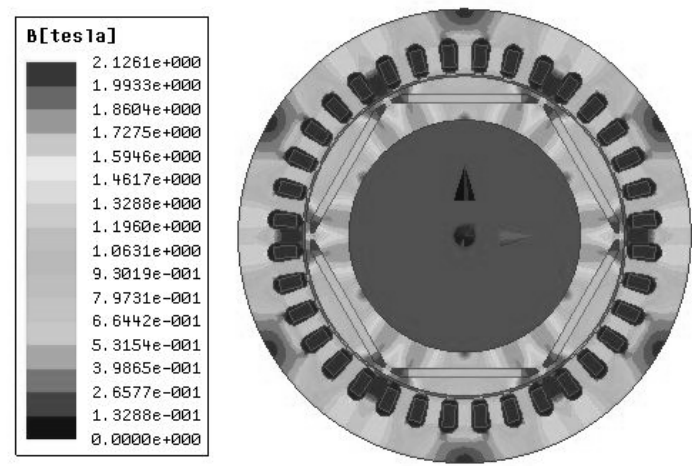

Fig.2 Steady magnetic field cloud distribution

The air-gap flux density distribution curve is shown in Fig.3(a) which the shape is a flat-topped waves.Make a FFT analysis to get Fig.3(b), it can be seen 3,5,7 harmonic content is relatively rich and the flux density of the fundamental amplitude is $0.75 \mathrm{~T}$.

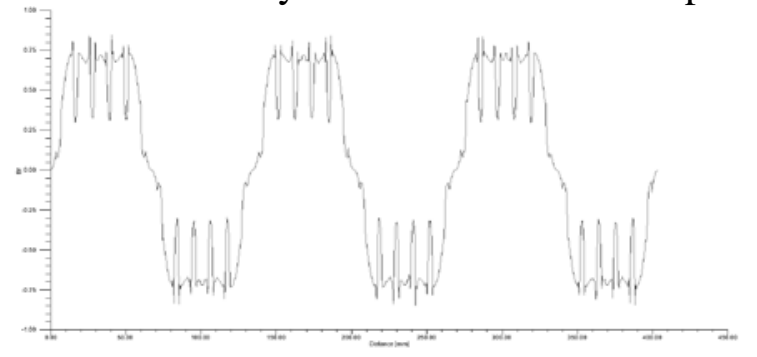

(a) Air gap flux density curve

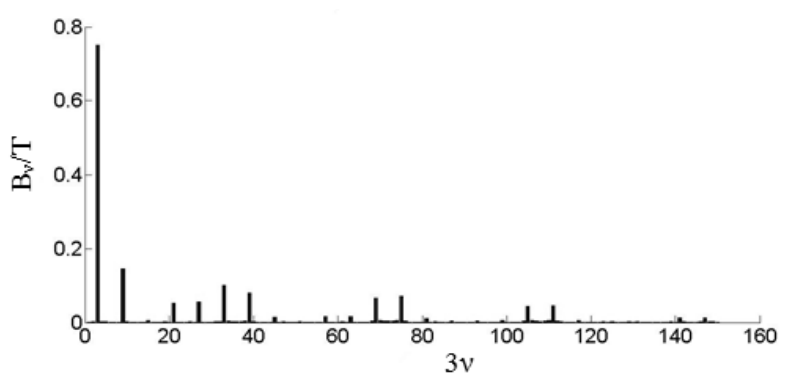

(b) FFT harmonic content analysis

Fig.3 Air gap flux density curve and FFT analysis

In addition, using the transient solver to get the current and torque of the motor. The steady value of current is $49 \mathrm{~A}$, the electromagnetic torque stability can be achieved to $108 \mathrm{Nm}$, with Siemens reference motor equivalent but the torque fluctuations. 


\section{The Motor Structure Optimization Design}

As can be seen from the air-gap flux density distribution curve in Fig.3(a), the air-gap flux density waveform contained a lot of harmonic wave is flat-topped rather than the ideal sine wave, which reduces the control accuracy, increase loss and torque ripple. For turning power electro-spindle, these defects will be more prominent, and therefore, its waveform optimization to be close to sinusoidal distribution is important. Considering the processing technology to achieve, a non-uniform air-gap of the rotor pole structure is proposed in Fig.4:

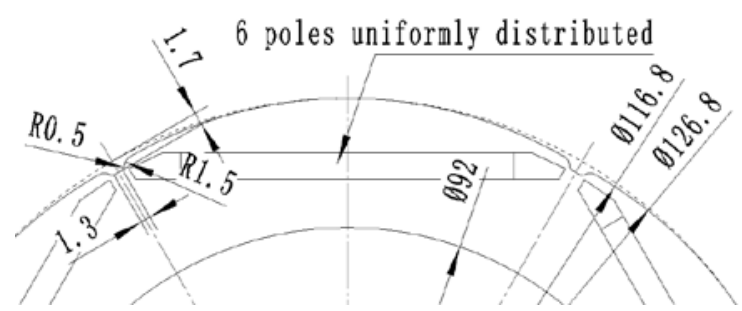

Fig.4 Uneven air-gap rotor structure $\mathrm{B}_{v}$

Using the same method to analysis the electromagnetic field of the uneven gap rotor structure by FEA, the air-gap flux density wave and three-phase no-load EMF curve are shown in Fig.5(a) and Fig.5(b). As we can see, the air-gap flux density of optimized rotor structure is close to sinusoidal waveform. Otherwise the no-load EMF values is $185 \mathrm{~V}$, compared to the rated voltage $220 \mathrm{~V}$ has leaving a considerable margin, so that the current rapid sinking when the motor starting, thus getting a better ability to respond quickly.

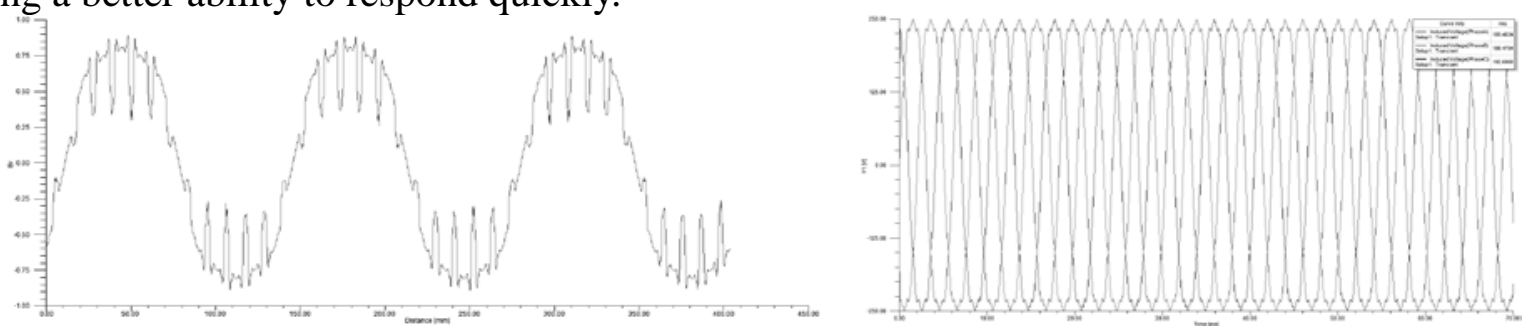

(a) Optimized air-gap flux density curve

(b) Optimized three-phase no-load EMF curve

Fig.5 Analysis curve of the optimized motor

Do the FFT analysis of Fig.5(a) and comparing with the result before optimization to get Fig.6(a), it can be seen 3,5,9,11,15 harmonic content of air-gap flux density ignificantly reduced, and the fundamental amplitude is $0.79 \mathrm{~T}$, which is improved $5.3 \%$. Electromagnetic torque contrast figure before and after optimization is shown in Fig.6(b). Obviously, the torque ripple has been reduced after optimized, which can enhance the stability of turning electro-spindle when machining parts.

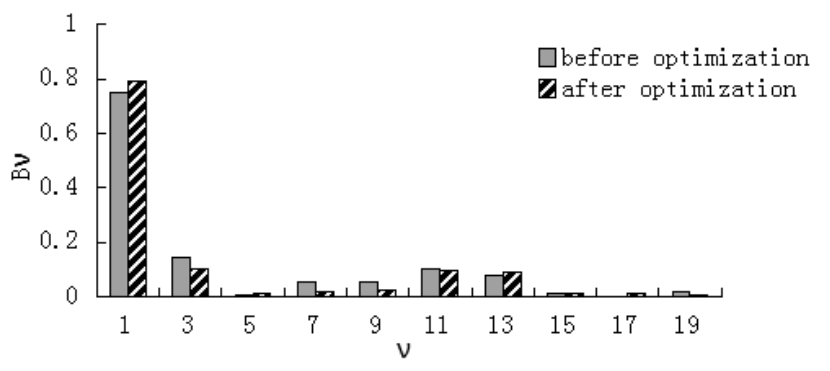

(a) Harmonic content contrast figure

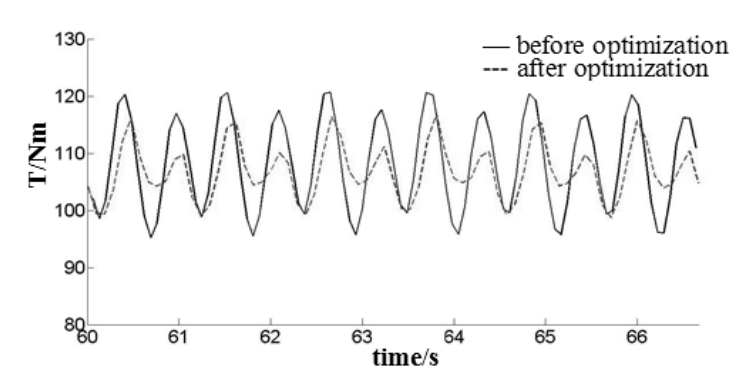

(b) Torque contrast figure

Fig.6 Contrast of two plan

\section{Weakening Capacity Checking}

Different from the electrically excited synchronous motor, the rotor excitation of PM synchronous motor is not adjustable, while the speed is proportional to the counter electromotive force generated by the permanent magnetic field, when the motor terminal voltage increases with the speed to a maximum output voltage of the inverter, only the reduce of the magnetic flux can 
continue to increase the speed of the motor. In the high speed region, the motor is required with a larger $d$-axis armature reaction, and a relatively small magnetic flux so that the speed of the motor continues to increase. In order to investigate the maximum achievable speed of the designed motor , its weakening capacity analysis is particularly important.

\section{1. $D-q$ axis Inductance Calculation}

The three-phase winding flux equation of PM synchronous motor is

$$
\left[\begin{array}{l}
\psi_{A} \\
\psi_{B} \\
\psi_{C}
\end{array}\right]=\left[\begin{array}{lll}
L_{A A} & L_{A B} & L_{A C} \\
L_{B A} & L_{B B} & L_{B C} \\
L_{C A} & L_{C B} & L_{C C}
\end{array}\right]\left[\begin{array}{l}
i_{A} \\
i_{B} \\
i_{C}
\end{array}\right]=L_{A B C}\left[\begin{array}{l}
i_{A} \\
i_{B} \\
i_{C}
\end{array}\right]
$$

According to the relationship between three-phase power and $d-q$ axis current:

$$
\begin{aligned}
& {\left[\begin{array}{l}
\psi_{d} \\
\psi_{q}
\end{array}\right]=\sqrt{\frac{2}{3}}\left[\begin{array}{ccc}
\cos \theta & \cos \left(\theta-\frac{2}{3} \pi\right) & \cos \left(\theta+\frac{2}{3} \pi\right) \\
\sin \theta & \sin \left(\theta-\frac{2}{3} \pi\right) & \cos \left(\theta+\frac{2}{3} \pi\right)
\end{array}\right]\left[\begin{array}{l}
\psi_{A} \\
\psi_{B} \\
\psi_{C}
\end{array}\right]=C^{T}\left[\begin{array}{l}
\psi_{A} \\
\psi_{B} \\
\psi_{C}
\end{array}\right]} \\
& {\left[\begin{array}{l}
i_{A} \\
i_{B} \\
i_{C}
\end{array}\right]=\sqrt{\frac{2}{3}}\left[\begin{array}{cc}
\cos \theta & \sin \theta \\
\cos \left(\theta-\frac{2}{3} \pi\right) & \sin \left(\theta-\frac{2}{3} \pi\right) \\
\cos \left(\theta+\frac{2}{3} \pi\right) & \sin \left(\theta+\frac{2}{3} \pi\right)
\end{array}\right]\left[\begin{array}{l}
i_{d} \\
i_{q}
\end{array}\right]=C\left[\begin{array}{l}
i_{d} \\
i_{q}
\end{array}\right]}
\end{aligned}
$$

So that

$$
L_{d q}=C^{T} L_{A B C} C
$$

Where, $L_{d q}=\left[\begin{array}{ll}L_{d d} & L_{d q} \\ L_{q d} & L_{q q}\end{array}\right]$ is the $d$-q inductance matrix. $L_{d d}$ is the $d$-axis inductance, $L_{q q}$ is the $q$-axis inductance.

As shown in Fig.7(a), the center line of the A-phase winding of stator is adjusted to coincide with the location of rotor $d$-axis, the initial position of the rotor angle $\theta$ (Thet) is $10^{\circ}$.Derivation of formula (3) to (6), the $i_{d}$ and $i_{q}$ current is setting as Fig.7(b), thus the current in ABC coordinate system is expressed as (7)

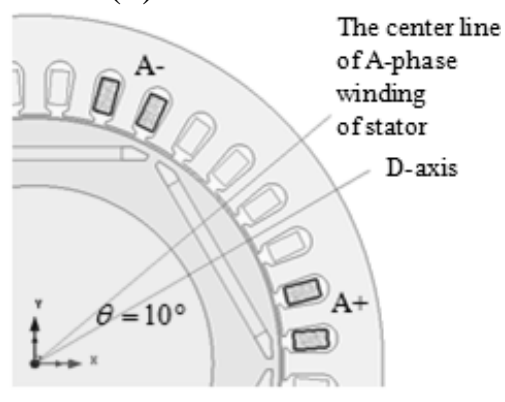

(a) Initial angle diagram

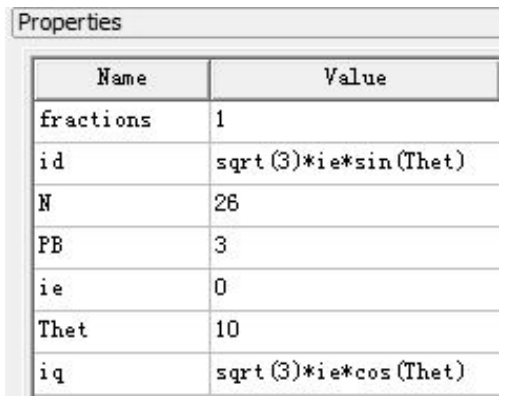

(b) Setting of $i_{d}$ and $i_{q}$

Fig.7 Setting of Ansoft

$$
\left\{\begin{array}{l}
i_{A}=\sqrt{\frac{2}{3}} i_{d} \frac{N}{P B} \\
i_{B}=\sqrt{\frac{2}{3}}\left(-\frac{1}{2} i_{d}-\frac{\sqrt{3}}{2} i_{q}\right) \frac{N}{P B} \\
i_{C}=\sqrt{\frac{2}{3}}\left(-\frac{1}{2} i_{d}+\frac{\sqrt{3}}{2} i_{q}\right) \frac{N}{P B}
\end{array}\right.
$$

Where, $\mathrm{N}$ - coil number of turns, $\mathrm{PB}$ - parallel branch number, ie - phase current RMS.

Add the excitation $i_{A}, i_{B}, i_{C}$ to windings and do static calculation to obtain the results of the three-phase inductor $L_{A B C}$ (unit $\mathrm{mH}$ ), which is shown in Fig.8: 


\begin{tabular}{|l|l|l|l|}
\hline & \multicolumn{1}{|c}{ winding $A$} & \multicolumn{1}{c|}{ winding $B$} & winding $C$ \\
\hline windingA & 0.024114 & -0.00083859 & -0.014398 \\
winding $B$ & -0.00083859 & 0.024122 & -0.014405 \\
windingC & -0.014398 & -0.014405 & 0.039342 \\
\hline
\end{tabular}

Fig.8 Three-phase inductance calculation results

2. Maximum weakening speed calculation deally

By motor learning formula, the no-load flux is about

$\psi=\frac{2}{\pi} \tau_{2} l_{e f} B_{\delta}=\frac{2}{\pi} \times 6 \times 0.15 \times 0.79=0.44 \mathrm{~Wb}$

When the motor terminal voltage and the current reaches a maximum value and the full current is all $d$-axis current component, ignoring the stator resistance, can get the highest ideal speed under common weak magnetic control strategy[5]

$$
\begin{aligned}
n_{\max } & =\frac{60 u_{\lim }}{2 \pi p\left|\psi_{f}-L_{d} i_{\lim }\right|} \\
& =\frac{60 \times 380}{6 \pi|0.44-0.00413 \times 60|} \\
& =6290 \mathrm{rpm}
\end{aligned}
$$

Where, $u_{\text {lim }}$ - maximumvoltage, $\psi_{f}$ - no-load magnetic line, $i_{\text {lim }}$ - maximum current.

\section{Conclusion}

In this paper, an electro-spindle for turning is designed by finite analysis software Ansoft, the main performance parameters distribution curves are obtained under steady-state and transient situation. On this basis, a non-uniform air gap is designed to optimize the structure of the rotor structure. The no-load flux density is $0.79 \mathrm{~T}$ after optimized in a stable situation, three-phase no-load EMF is $185 \mathrm{~V}$, and the torque is $108 \mathrm{Nm}$ which has been increased compared with Siemens reference motor. Otherwise, the flux density increased, torque ripple reduced after optimization, which is better to meet the design requirements and also verify the feasibility of the design and analysis methods. Finally, the weakening maximum speed under ideal conditions is analysised and calculated. The motor can reach a maximum speed of 6290rpm, which meets for the twice weakening speed design requirements.

\section{Acknowledgement}

In this paper, the research was sponsored by Program for LNIRT in university (LT2013006).

\section{References}

[1] Hong Ronghua. Design and thermal characteristic research on high speed permanent magnetic synchronous motorized spindle[D]. Harbin Institute of Technology University. 2007.

[2] Tang Renyuan. Modern permanent magnet motor theory and design. Beijing: China Machine Press. 1997.

[3] Ma Juan. Design and optimization of three-phase asynchronous start permanent magnet synchronous motor[D]. Zhejiang University. 2007.

[4] W.Czermin, F.Aschenbrenner, H.Weiss, Design of Power Electronics Driven PMSM With Constant Torque by Special Magnetic Circuit and Permanent Magnet Configuration, APEIE-2006, pages 211 216.

[5] Guo Zhenhong. Study and design of the spindle pemrnaent magnet snyehronous motor and its drive system[D]. Shenyang University of Techonoly,1999. 